\title{
Integration of GIS and AHP for Suitable Site Selection of Domestic Wastewater Treatment Plant: A Case Study of Akkaraipattu Municipal Council
}

\author{
D.S. Munasinghe*, P.G.R.N.I. Pussella, M.D.E.K. Gunathilaka \\ Department of Surveying and Geodesy, Sabaragamuwa University, Sri Lanka \\ *deepika@geo.sab.ac.lk
}

\begin{abstract}
Domestic wastewater has been defined as the water discharged from a community after it has been fouled by various uses and containing waste. An inappropriate releasing of domestic waste water is a challenge for the ecosystem and human health. Hence, to prevent environmental pollution, one of the aims of the wastewater treatment is to recover water for further consumptions, including agricultural purposes. If proper location for the treatment plant is not selected, it may lead to soil degradation and ground water pollution. Thus, this study aimed to select a suitable site for domestic wastewater treatment plant (DWWTP). It is an important for the sustainable treatment and reuse of wastewater coverage and it reduces the social and environmental impacts. The study was carried out by using Geographic Information System (GIS), which enabled an efficient combination of all factors influencing the suitability of a site, and included the area of Akkaraipattu Municipal Council. To ensure the technical feasibility, environmental sustainability and social acceptability, a number of factors were considered for the site selection, including the factors such as temperature, rainfall, wind direction and speed, soil, slope, land use, accessibility, distance to surface waters, distance to ground water. After that, analytical hierarchy process (AHP) weight analyse method was carried out for selected factors, to give a rating system in the same numeric values. Each factor was mapped into the GIS system as an individual data layer. The suitability map, which was produced by overlaying all data layers, divided into four categories according to the suitability. Finally, a GIS model was built as an example for similar studies in future. In order to locate the site with the minimum effect on the environment, field verification procedure was carried out to determine the best and optimal site.
\end{abstract}

Keywords: GIS, AHP, Domestic waste water treatment plant 